\title{
Assessing academic writing on a pre-sessional EAP course: Designing assessment which supports learning
}

\author{
Martin Seviour ${ }^{*}$ \\ School of Arts and Humanities, Nottingham Trent University, Burton Street, Nottingham, NG1 4BU, United Kingdom
}

\section{A R T I C L E I N F O}

\section{Article history:}

Available online 15 April 2015

\section{Keywords:}

Pre-sessional

Assessment

Writing

Formative

Engagement

Feedback

\begin{abstract}
A B S T R A C T
Pre-sessional EAP courses in the UK fulfil a difficult dual role. Not only are they charged with helping students learn the academic language and literacy skills they will require on their degree courses, but they are also expected to summatively assess those skills in order to decide on the readiness of students to begin English medium degree study. This creates tension between assessment and learning. Students are often extrinsically motivated by the need for a passing grade rather than focussing on the learning gains they make throughout the course. For this reason it is important that the approach to assessment on pre-sessional courses actually supports learning. This paper outlines the approach taken to the assessment of academic writing on the PEAP course at Nottingham Trent University. It describes how the assessment was redesigned to emphasise process over end product and to maximise early and sustained student engagement. This was achieved by careful scaffolding of the writing process, the strategic use of summative elements of the assessment, and an emphasis on formative feedback, reflection, and understanding of the assessment criteria. The paper considers how this approach to assessment is supporting student learning but also points out some ongoing concerns.
\end{abstract}

(c) 2015 Elsevier Ltd. All rights reserved.

\section{Introduction}

As uncomfortable as it may make many university teachers feel, it is difficult to disagree with Gibbs' (2006) assertion that "assessment frames learning, creates learning activity and orients all aspects of learning" (p.23). Pre-sessional EAP courses are no exception to this. These courses are typically high stakes with students required to reach specific grades in assessments before progressing to their various degree courses or PhD study. International students on pre-sessional courses are no less strategic than others in the way they focus their time and efforts on what they believe will bring them the grades they require to pass. This focus on assessment and grades often seems to undermine what pre-sessional teachers perceive as their key role of facilitating the learning of the academic language and skills students need to fully engage with their academic courses. Because of this obvious tension between assessment and learning it is critical that the assessment strategy chosen actually leads to effective learning. Boud (2000) puts this neatly when he describes assessment activities as having to do 'double duty' (p.159) since they must encompass both formative assessment for learning as well as summative for certification. This paper will outline some recent innovations in the assessment of one key component of the pre-sessional EAP (PEAP) course at

\footnotetext{
* Corresponding author.

E-mail address: martin.seviour@ntu.ac.uk.
} 
Nottingham Trent University and evaluate the extent to which these innovations have led to assessment which actually supports students' learning rather than detracting from it.

Like many other UK pre-sessionals, PEAP is a year-round course with multiple entry points depending on the entry level proficiency of students. The summer months see the largest number of students (typically 250-300) aiming to reach the required grades in the final assessment before beginning their degree courses in October. Class sizes during this period range from 10 to 14 students. Over the last five years the assessment of PEAP has undergone a fairly rapid evolution in response to changing demands from both inside and outside the University. Visa requirements for international students have dictated that they are formally assessed in all four language skills and there has also been some pressure internally to ensure that the number of students who progress from PEAP remains high. From a situation in 2009/10 when PEAP students were assessed only by means of an academic essay and an individual presentation we now have a validated course with five assessment elements (a coursework essay, exams in academic reading, listening and writing and a group presentation) each weighted at $20 \%$. Work is ongoing in all these elements to align them more closely with the course learning outcomes but it is in the coursework essay where the most innovative changes have been introduced. In its previous form, the assessment was very much focussed on the end product, there was little scaffolding of the writing process itself through classroom input and limited opportunities for students to receive formative feedback or to reflect on their writing. In short, student engagement with the task was at best sporadic. There was a clear need to remodel this assessment so that it better supported student learning.

\section{Redesigning the assessment of the academic essay}

In redesigning the coursework essay component of the PEAP course we used Gibbs and Simpson' s (2004) conditions under which assessment supports students' learning' (p.11) guide our choice of learning and assessment activities. Gibbs and Simpson outline eleven such conditions relating to the quantity, distribution, quality and level of student effort required on a particular assessment, the quantity, timing and quality of feedback provided to students and student response to that feedback. In summary, these conditions suggest that to support learning, a particular assessment task should require significant student effort which is distributed across a number of weeks rather than being concentrated at the end of the course and should lead to engaged learning activity in which students take a deep approach to learning. 'Learning friendly' assessment tasks should also articulate challenging but clear goals to students so that they can selfmonitor. Feedback on assessment should be frequent, timely, detailed, understandable and clearly linked to criteria. Finally students should have opportunities to respond to feedback in order to improve their work and their learning (Gibbs \& Simpson, 2004.)

Perhaps the overriding aim of the redesign of the assessed coursework essay component was to ensure that it allowed a shift away from a fixation on the end product towards writing as a multi-stage process. Consideration was given to using portfolio assessment since it allows for a broader evaluation of a student's writing development than does a 'single-shot' approach (Weigle, 2002). However, time constraints on PEAP (the assessed part of the pre-sessional course is only 6 weeks in duration) meant that it was unrealistic to expect students to produce several pieces of writing in different genres and for different purposes and audiences which is a key requirement of a portfolio (Hamp-Lyons \& Condon, 2000). Instead we opted for an approach which would allow us to assess the development of a single 2500 word academic essay over a 6 week period. This is closer in format to what has been termed the 'processfolio' (see, for example, Pearson, 2015) since it aims to capture the steps taken to produce a single piece of writing rather than a selection of different pieces produced over time. Unlike the processfolio, however, our approach does not involve student selection of evidence of learning.

Fig. 1 below illustrates the various stages in the assessment of the academic writing process on the 6-week PEAP course and indicates the points at which formative and summative assessment take place and where feedback of different types is provided to students. The following section outlines how this approach aims to support student learning through creating and sustaining engagement, providing quality feedback to students and allowing them time to reflect, respond and improve, and ensuring that students are fully aware of the various assessment criteria used and what is expected of them at each stage.

\section{Assessment which creates and sustains student engagement}

Hu and Kuh (2002) define engagement as "the quality of effort students themselves devote to educationally purposeful activities that contribute directly to desired outcomes" (p.555). It is generally assumed that students with high levels of intrinsic motivation also have higher levels of engagement in learning and achievement than students who do not. Yet, experience suggests that for university students, extrinsic motivation, in particular the desire to obtain the necessary grades to pass a course, plays a significant role in their approach to study. Pre-sessional students are no exception to this and they are often 'fixated' on the passing grade and on the summative assessment at the end of the course rather than on achieving learning gains and making use of the formative feedback and opportunities for reflection along the way. This can in turn lead to students leaving assessed work until deadlines loom, rather than developing a text over a number of weeks. The outcome of this is that work is rushed and underachieving and often displays bad academic practice including textual copying, plagiarism and collusion or, at worst, contract cheating.

To avoid the above scenario we have attempted to arrange the summative assessment to put more emphasis on academic writing as a process but still meet the students' need to know their grade. To achieve this we have reduced the weighting of 


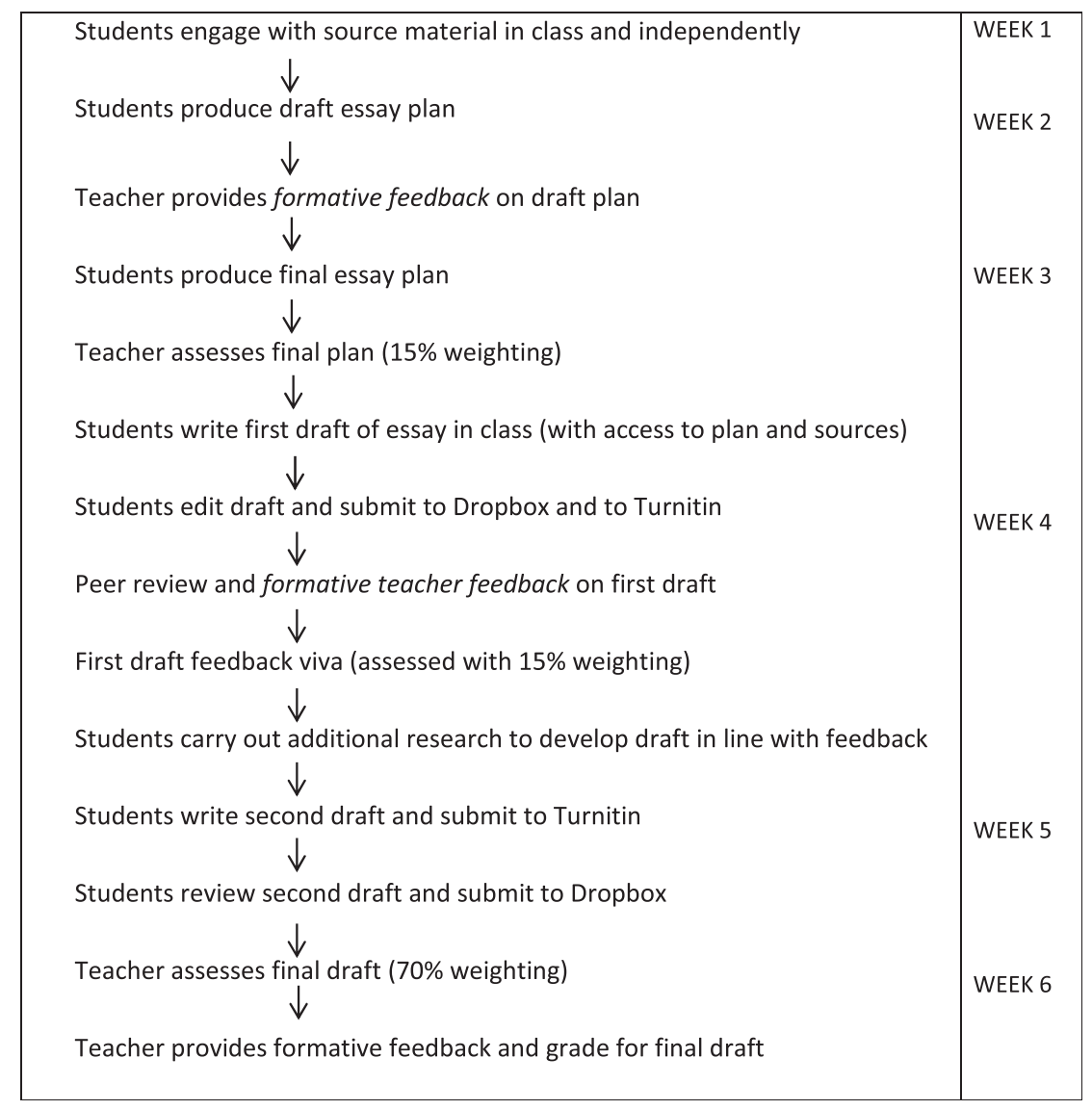

Fig. 1. Stages in the coursework essay learning and assessment process.

the final draft to $70 \%$ and introduced two further summative elements to the assessment, the essay plan and the feedback viva, each weighted at $15 \%$. The aim here is to use the powerful extrinsic motivation of grades to enhance intrinsic motivation rather than undermine it. The interrelationship between intrinsic and extrinsic motivation is a complex one but as Higgins, Hartley, and Skelton (2002) suggest "many of today's students have a consumerist awareness reflected in a focus on achieving a grade alongside intrinsic motivations" (p.61). The weightings of the first two assessment elements are small enough to be non-threatening but significant enough to motivate students to become engaged early on, put some marks 'in the bank', and relieve some of the pressure they feel regarding their ability to produce a satisfactory end product. The rationale of these two elements and their role in promoting engagement and learning is outlined below.

\subsection{The essay plan}

The first summatively assessed element in the writing process is the essay plan. At the end of the second week of the 6week course, having encountered and considered the essay topic and question, the assessment criteria and a number of relevant sources, students are asked to produce a detailed outline of their proposed essay. Some input is given on the principles and techniques of planning and students are provided with a template to help them with layout. They draft their essay plan and receive formative feedback before submitting a final plan which the teacher grades. The final plan is assessed according to a limited set of criteria which focus on the clarity of the thesis statement and the way the plan illustrates the intended structure of the essay, the development of the thesis and where sources will be used to support it.

Although essay planning is a common item on academic writing courses and students are encouraged to plan before drafting essays, these plans do not always receive feedback and are rarely formally assessed. However, there is evidence that obliging students to plan carefully and assessing these plans summatively can lead to improved essay grades and also help students to get started early on the assignment and to build their confidence (Kiernan, Lawrence, \& Sankey, 2006). Evidence from the PEAP course supports these findings. Students take the planning task very seriously and it seems to promote early critical engagement with the topic and the academic sources. Teachers report that planning helps students to approach essay writing in a systematic way and to be more in control of the process. 


\subsection{The feedback viva}

The second formally assessed element of the writing process is the feedback viva. This is a 15 min semi-structured dialogue between the student and the teacher. Prior to the viva students have submitted the first draft of their essay and received written comments on it from the teacher. They receive additional feedback on their essay from a peer review exercise conducted in class and from a Turnitin originality report. During the viva itself, the teacher asks questions about the student's essay and the feedback received on it. Students are assessed according to their understanding of their essay and the arguments within it, and their ability to reflect on the feedback and to articulate how they intend to develop and improve the essay.

The design and implementation of the feedback viva on PEAP drew on a number of published accounts of similar initiatives involving the use of oral interviews as part of the assessment of a written assignment (see Carless, 2002; Franks \& Hanscomb, 2012; Prowse, Duncan, Hughes, \& Burke, 2007). All these use the viva to encourage and incentivise students to take responsibility for their work, to actively engage with the feedback received on their writing, and to reflect on how it can be used to make improvements. Results from these initiatives suggest that the formally assessed viva has clear advantages over providing only formative written or oral feedback. A survey of PEAP students' views on the feedback viva indicate that it helps them to engage more deeply with the writing task and obliges them to read and reflect more carefully on the feedback. Like the assessed essay plan it seems to develop their confidence in tackling the assignment and managing the time and effort required.

\subsection{Engagement through challenge and scaffolding}

A well-designed academic writing assignment should challenge the more able students but should not be so challenging that less able students struggle to get started and become disengaged. As Reid and Kroll (1995, cited in Weigle, 2002) suggest, it is important that the writing task set can be accomplished within the specific parameters of the assessment and is not 'outside the expertise, experience or researchability of the student writer' (p.183). The writing assignments encountered on the PEAP course are certainly challenging, especially since our students are typically relatively novice academic writers. To tackle the assignment students must use a range of skills and language resources to synthesise ideas from different sources and develop their own voice. However, unlike many pre-sessional courses, PEAP does not assess discipline-specific writing. Instead, all students are asked to write on the same topic of more general interest (e.g. the impact of tourism on destinations or the effects of globalisation on aspects of culture). In order to develop their response to the essay prompt, the students are provided with the same set of source texts all related to the topic but representing different genres (e.g. textbook chapters, journal articles and lectures). Only at second draft stage are students required to research additional appropriate sources to further extend and improve their essay.

Clearly this approach has certain disadvantages. Firstly, it does not allow students to write on topics or in genres specific to their chosen discipline, an aspect of writing assessment which is seen by some EAP practitioners as very important (see for example Alexander, Argent, \& Spencer, 2008, p.201). Secondly, the approach deliberately restricts the amount of independent research required and limits student choice over the material they read and use in their writing. Although autonomy maybe considered a contributing factor to engagement, surrendering a degree of student autonomy allows for a more controlled and scaffolded approach which is particularly important with students of mixed levels of competence and experience. With students working simultaneously on the same writing task and encountering the same source material, teachers are able to facilitate whole-class and group activities (including collaborative discussion and brainstorming, notemaking, summarising, etc.) which support reading, planning and drafting and help students develop the functional language they need. Limiting students (at least initially) to a small set of prescribed but carefully chosen source material enables teachers to focus on developing key critical reading skills and encouraging students to interrogate texts more thoroughly rather than spending time searching for relevant material in the library or on the internet. In short, the approach allows for scaffolded, purposeful activities which are very closely connected to the assessed writing task and which also promote collaboration. All of these features serve to increase engagement with the task and therefore learning.

\section{Creating opportunities for feedback and engagement with assessment criteria}

Feedback on assessed tasks can have a powerful influence on learning. It can empower students to improve their performance by engaging and motivating them and by providing them with alternative strategies and directions as well as corrective advice (Hattie \& Timperley, 2007). However, for feedback to realise its potential it should be built into the structure of a syllabus and be detailed, frequent and timely (Gibbs \& Simpson, 2004). The PEAP course offers students multiple opportunities to receive feedback on their writing from different sources; their teacher, their peers and Turnitin (see Fig. 1).

Teacher feedback is given at all key stages of the writing process - the plan, the first draft and the final draft - and in a variety of forms (rubric, written commentary, correction using a code and oral comments). The focus of all this teacher feedback is on reinforcing what has been learnt rather than judging the writer. The teacher aims to help students realise the potential of their texts through providing detailed corrective advice which helps them prioritize areas for improvement without overwhelming them. This is by no means an easy task for teachers. As Ferris (2001, p.314) comments "teacher response to student writing is an interaction filled with complexity and possible communication breakdowns". To help ensure 
the quality and consistency of teacher feedback we have established feedback benchmarks, provided teachers with exemplars and made feedback a key topic in our pre-course teacher induction. In addition, mentoring of feedback has been introduced which allows teachers to receive advice from experienced colleagues on the feedback they are writing for students. This is particularly important on a course where teachers come from a variety of teaching contexts and so have widely differing experience of and attitudes to providing feedback on writing. Helping teachers improve the quality of the feedback in turn makes it more likely that students will engage with it, respond to it and learn from the process.

Peer feedback is also an integral part of the coursework essay teaching and assessment process on the PEAP course (see Fig. 1). Peer response, like writing and learning, is a social process and allows students to receive feedback in a nonthreatening and non-judgemental environment (Hyland, 2002). It is perhaps understandable that most students will value comments from teachers more highly than those from peers. However, careful preparation for peer feedback, including training learners in giving and receiving feedback, the use of response sheets and judicious pairing of students, can make it a very positive learning experience. PEAP students are expected to discuss their response to the peer feedback on their draft during the feedback viva, which encourages them to take the peer exercise seriously and engage with the comments and suggestions made by their partner.

A third source of feedback provided to students is the Turnitin originality report which students obtain for both drafts of their essay by submitting their writing to a Turnitin drop box located on the University VLE. The resulting reports highlight similarities to existing sources (including other student essays) and help students to reflect carefully on how they have used their sources to develop their essay. This use of Turnitin as a formative tool rather than as a deterrent is in increasing and there is evidence that it can help students understand the concept of plagiarism (Buckley \& Cowap, 2013), improve referencing and paraphrasing (Rolfe, 2011)and reassure them when they are on the right track (Whittle \& Murdoch-Eaton, 2008). Although more research is needed to understand how students actually use the report to improve their texts, it does seem clear that it encourages them to take responsibility for their writing which is a prerequisite for learning.

Of course, the feedback provided to students in these forms only contributes to learning if it can be understood and responded to. To ensure that this happens teachers need to be trained in successful feedback techniques and students also need training in how to interpret feedback and relate it to the assessment criteria for a particular task. This is true not only for the written and oral comments they receive from teachers and peers but also for the more impersonal feedback contained in the Turnitin report.

In order for assessment activities to support learning students must be given frequent opportunities to explore and engage with the criteria which apply to that activity (Boud \& Falchikov, 2006 p. 408). This means that assessment criteria should be explicit and accessible to students so that they can be clear about what is required of them, how it will be assessed and what constitutes an acceptable performance. Only when they are familiar with the criteria can they begin to assess their own writing and decide on which aspects of a draft need further development. PEAP students are provided with detailed criteria for all the components of the writing assessment and various classroom and independent learning activities encourage them to examine and discuss the language and meaning of the criteria and focus on what they need to do to improve their writing to the required standard.

\section{Conclusion}

The approach to the assessment of the coursework essay component on PEAP has shifted from an emphasis on the end product to a much greater focus on writing as a process. This shift has enabled the development of an assessment which seems to support student learning of key academic writing skills. The strategic use of both summative and formative components of the assessment has led to earlier and more meaningful engagement in the assignment. The assessment is certainly challenging, but the scaffolded approach and the importance given to feedback and reflection seems to allow students to become confident and take some control over the process. As a result we see fewer cases of plagiarism and more examples of students trying to use sources to develop their own voice in their own words. Although, of course, some student writing still contains frequent surface error and structural problems, there is also evidence of considerable improvement made between drafts, which is an indication of learning.

However, some issues remain concerning the viability and validity of the approach. Firstly, it is very demanding on teachers' time. Each of the assessed components require standardisation, marking and moderation and the focus on feedback also means that teachers are involved in crafting comments and suggestions for students which will help them improve. Since the course is only six weeks in duration, students too are rather short of time to adequately reflect on drafts and feedback and make revisions. The fact that students are not differentiated according to discipline could also be seen as a weakness. This generic approach means that students may not be exposed to the genres of writing common in their discipline. For instance, students are currently assessed on a discursive essay although in certain disciplines this genre is far less common than the report. Finally the approach has been criticized for being so scaffolded that it does not adequately assess a student's ability to write independently.

This latter issue relates to the 'double duty' which assessment must often perform - to assess students for certification or progression and to help them learn. Further research into the extent to which students who successfully complete the PEAP course actually carry over key skills to their degree study may help reveal whether our approach to the assessment of academic writing adequately fulfils this dual role. We also need to know more about how students themselves perceive and 
manage the tension between needing to obtain a passing grade in an assessment and more intrinsic motivations to engage in learning from it.

\section{References}

Alexander, O., Argent, S., \& Spencer, J. (2008). EAP essentials: A teacher's guide to principles and practice. Reading: Garnet.

Boud, D. (2000). Sustainable Assessment: rethinking assessment for the learning society. Studies in Continuing Education, 22(2), 151-167.

Boud, D., \& Falchikov, N. (2006). Aligning assessment with long-term learning. Assessment and evaluation in Higher Education, 31(4), 399-413.

Buckley, E., \& Cowap, L. (2013). An evaluation of the use of turnitin for electronic submission and marking and as a formative feedback tool from an educator's perspective. British Journal of Educational Technology, 44(4), 562-570.

Carless, D. (2002). The mini-viva as a tool to enhance assessment for learning. Assessment and Evaluation in Higher Education, 27(4), $353-363$.

Ferris, D. (2001). Teaching writing for academic purposes. In J. Flowerdew, \& M. Peacock (Eds.), Research perspectives on english for academic purposes (pp. 298-314). Cambridge: CUP.

Franks, B., \& Hanscomb, S. (2012). Learning through reflective dialogue: assessing the effectiveness of feedback vivas. Discourse: Learning and Teaching in Philosophical and Religious Studies. ISSN: 1741-4164, 12(1). Available at: http://www.heacademy.ac.uk/journals/discourse-journal Accessed 2.02.15..

Gibbs, G. (2006). How assessment frames student learning. In C. Bryan, \& K. Klegg (Eds.), Innovative assessment in higher education (pp. 23-36). Abingdon: Routledge.

Gibbs, G., \& Simpson, C. (2004). Conditions under which assessment supports students' learning. Learning and Teaching in Higher Education, 1, 3-31.

Hamp-Lyons, L., \& Condon, W. (2000). Assessing the portfolio: Principles for practice, theory and research. Cresskill, NJ: Hampton Press.

Hattie, J., \& Timperley, H. (2007). The power of feedback. Review of Educational Research, 77(1), 81-112.

Higgins, R., Hartley, P., \& Skelton, A. (2002). The conscientious consumer: reconsidering the role of assessment feedback in student learning. Studies in Higher Education, 27(1), 53-64.

Hu, S., \& Kuh, G. D. (2002). Being (Dis)Engaged in educationally purposeful activities: the influences of student and institutional characteristics. Research in Higher Education, 43(5), 555-575.

Hyland, K. (2002). Second language writing. Cambridge: CUP.

Kiernan, E., Lawrence, J., \& Sankey, M. (2006). Preliminary essay plans: Assisting students to engage academic literacy in a first year communication course. Paper presented at the 9th Pacific rim first year in higher education Conference: Engaging students. Griffith University, Gold Coast, Australia, 12-14 July. Available at http://www.ibrarian.net/navon/page.jsp?paperid=12424428\&searchTerm=academic + communication Accessed 20.02.15.

Pearson, J. (2015). Participation and control in EAP writing assessment. Poster presented at EALTA SIG Seminar on the assessment of writing and assessment for academic purposes, university of Warwick, February 5-7, 2015. Available at http://www.ealta.eu.org/conference/2013/docs/WRAP-SIG/Jayne\% 20Pearson\%20poster\%20presentat_on\%20EALTA\%202013.pdf Accessed 02.02.15.

Prowse, S., Duncan, N., Hughes, J., \& Burke, D. (2007). ‘...do that and I'll raise your grade’. Innovative module design and recursive feedback. Teaching in Higher Education, 12(4), 437-445.

Reid, J., \& Kroll, B. (1995). Designing and assessing effective classroom writing assignments for NES and ESL students. Journal of Second Language Writing, $4(1), 17-41$.

Rolfe, V. (2011). Can turnitin be used to provide instant formative feedback? British Journal of Educational Technology, 24(4), 701-710.

Weigle, S. (2002). Assessing writing. Cambridge: CUP.

Whittle, S. R., \& Murdoch-Eaton, D. G. (2008). Learning about plagiarism using turnitin detection software. Medical Education, $42,528$.

Martin Seviour is Senior Lecturer in EFL/TESOL and Programme Leader for Pre-sessional English at Nottingham Trent University. He has previously worked as a teacher, teacher trainer and materials developer in Sierra Leone, Finland, Mongolia, China and Uzbekistan. His interests lie in the areas of assessment and EAP teacher development. 